\title{
Los extranjeros y la historiografía modernista
}

\author{
Óscar Recio Morales ${ }^{1}$ \\ Profesor Docente Investigador Ramón y Cajal \\ Universidad Complutense de Madrid \\ Departamento de Historia Moderna \\ Facultad de Geografía e Historia \\ $\mathrm{C} /$ Profesor Aranguren, $\mathrm{s} / \mathrm{n}$. Edificio B \\ 28040 Ciudad Universitaria (Madrid), España \\ orecio@pdi.ucm.es
}

Fecha de recepción: 01/06/2011

Fecha de aceptación: 15/12/2011

\begin{abstract}
RESUMEN
El papel de los extranjeros en la Europa moderna ha sido inversamente proporcional a la atención historiográfica recibida. Este es también el caso de España. Aunque ya desde la década de 1960 el profesor Domínguez Ortiz llamó la atención sobre el enorme vacío historiográfico sobre estas comunidades, sólo a partir de los 90 se ha comenzado a estudiar de forma sistemática las actividades de los individuos y redes de origen extra-peninsular operativos en la Monarquía hispánica. No obstante, los avances en esta dirección quedan todavía lejos del nivel alcanzado en otros campos por la moderna historiografía. Esta contribución indaga en las posibles causas de este retraso y hace un repaso a las contribuciones más destacadas en los principales ámbitos profesionales de mayor presencia extranjera: finanzas y comercio, ejército, corte y administración, industria y cultura.
\end{abstract}

Palabras clave: extranjeros, España, historiografía, finanzas, comercio, ejército, corte, administración, industria, cultura.

\section{Foreigners in Early Modern Historiography}

\begin{abstract}
The role of foreigners in early modern Europe was inversely proportional to the attention received by Historiography. This is also the case of Spain. Although already from 1960 the Spanish scholar Domínguez Ortiz called attention to the gap on the study of foreign communities, only since the $1990 \mathrm{~s}$ research has begun to study systematically the activities of foreigners in Spain. However, progress in this direction is still far from the extraordinary results achieved in other areas by modern historiography. This paper addresses the possible causes of this delay and it presents also an overview of the most outstanding contributions on the role of foreigners in the Spanish finance and trade, the army, the court, the administration and industry.
\end{abstract}

Key words: foreigners, Spain, Historiography, finance, trade, army, Court, bureaucracy, industry, culture.

1 Esta contribución ha sido posible gracias al proyecto MICINN-Fondo Social Europeo «Ramón y Cajal 20082013» adscrito al Dpto. de Historia Moderna de la Universidad Complutense de Madrid, al proyecto de investigación MICINN "Proyección política y social de la comunidad irlandesa en la Monarquía hispánica y en la América colonial de la Edad Moderna (siglos XVI-XVIII)", HAR2009-11339 (subprograma HIST) y al proyecto DIGERINS 094/04 para la promoción y difusión de la Cultura de Defensa 2011 del Ministerio de Defensa (España). 


\section{INTRODUCCIÓN}

Desde mediados del siglo XV los europeos fueron protagonistas de la primera expansión global. El fenómeno migratorio transoceánico subsiguiente ha recibido (sigue recibiendo) una gran atención. En cambio, el estudio de las migraciones intraeuropeas y la participación de distintos individuos y comunidades no regnícolas en distintos territorios es algo más reciente. Esta expansión europea fue fragmentada por las distintas historiografías en función de su ámbito nacional y el papel de los extranjeros al interno de Europa quedó como un accidente en el proceso de construcción de la nación-estado. Hoy día los historiadores trabajan cada vez más desde un punto de vista transnacional, pero los programas de historia -desde la escuela hasta la universidad-, han sido establecidos a través de un largo proceso de institucionalización política. Los libros escolares, los programas de historia, el imaginario colectivo y la política tardarán en desprenderse de la "edad de oro" de cada país.

Dado que en el proceso de construcción-invención de la nación-estado la identidad nacional se construyó por oposición a otras identidades (reivindicando la originalidad de escritores o artistas por encima de las influencias externas y reforzando o inventando los estereotipos de "el otro"), la historiografía oficial denigró la labor de muchos de los extranjeros cuyo punto de referencia a lo largo del antiguo régimen era el monarca, más que la nación, tal y como iba a ser representada desde mediados del XVIII, pero con mayor claridad en el XIX. En la mayoría de los casos, sin embargo, más que una oposición frontal a los extranjeros, fue el olvido el que jugó un papel fundamental en cada uno de los Libros de la Patria. Si alguno de estos extranjeros había cumplido una gesta excepcional se le incorporó a la comunidad nacional. Esta "nacionalización forzada" fue un fenómeno a escala europeo que sigue vigente en nuestros días. Pocos dudarían de que Mozart no fuera tan "austriaco" como Ötzi (el "hombre de los hielos" encontrado en el glaciar alpino de Ötztal en 1991, hasta que se supo que sus restos estaban depositados, por escasos metros, en el lado italiano de la frontera) ${ }^{2}$. En algunos casos será el ADN el que permitirá aclarar, de una vez por todas, la "verdadera nacionalidad del sujeto"3.

Como en el resto de Europa, si exceptuamos los estudios jurídicos sobre la posición legal de los extranjeros, los análisis sobre los individuos y comunidades de origen extra peninsular en la Monarquía hispánica son relativamente recientes. En la primera parte de esta contribución afrontaremos las posibles causas de este retraso y

\footnotetext{
2 Salzburgo, ciudad natal de Mozart (1756-1791) era en la época un arzobispado independiente del Sacro Imperio Romano Germánico y fue sólo completamente incorporada a la Monarquía habsbúrgica en 1816. Ötzi fue encontrado en Südtirol, región de lengua y cultura germánica, pero bajo soberanía italiana. Südtirol había pertenecido al Imperio habsbúrgico, pero nunca perteneció a la República de Austria. Un original estudio sobre el proceso de construcción de la identidad moderna austriaca en Beller, Steven: Historia de Austria, Madrid, Akal, 2009.

3 Colón ha sido objeto de sendos proyectos en el Laboratorio de Identificación Genética de la Universidad de Granada y en el Departamento de Antropología Molecular de la Universidad de Tor Vergata, Roma. Ambos proyectos han recibido una extensa cobertura en prensa y en la mayoría de los casos lo que ha trascendido al público general ha sido que su objetivo era determinar de una vez por todas la nacionalidad de Colón. Para el proyecto granadino se comenzaron a realizar pruebas de ADN a 120 catalanes con el apellido Colom y para el proyecto italiano se enviaron 250 cartas-kit a varones lígures con el apellido Colombo, acompañadas de las instrucciones para dejar una muestra de saliva que sería posteriormente analizada en laboratorio.
} 
haremos un recorrido por las principales contribuciones de carácter general al tema; en la segunda parte nos aproximamos a las aportaciones más destacadas, siguiendo los sectores profesionales que contaron con una mayor presencia de extranjeros: finanzas y comercio, ejército, corte y administración, artesanía e industria. Tanto en la contribución de Tamar Herzog a este volumen como en las otras tres dedicadas a los extranjeros en la América española y Filipinas se encontrará abundante bibliografía sobre dichos espacios, por lo que nosotros limitaremos nuestro campo de estudio al espacio peninsular.

\section{UNAAPROXIMACIÓN HISTORIOGRÁFICA RECIENTE Y TRANSVERSAL}

Si alguien se acerca al tema de los extranjeros en España y lee las fuentes de la época, lo primero que advertirá es que sus actividades no gozaban de buena prensa. Las críticas hacia su papel en las finanzas y comercio peninsular se arrastraban ya desde tiempos de Carlos V (él mismo representante de una dinastía "extranjera") y se intensificaron con la crisis económica de la primera mitad del XVII ${ }^{4}$. Muchos de los discursos arbitristas contra los extranjeros fueron recogidos por los reformadores y proyectistas del XVIII, y algunas de las obras del XVII fueron reeditadas con este fin. Sancho de Moncada es un buen ejemplo. Sus famosos ocho Discursos (1619) fueron reeditados en 1746 como Restauración política de España. Su opinión sobre el papel distorsionador de los extranjeros en la economía española no ofrece lugar a dudas, y ni siquiera el monarca se salva de la crítica: "Afrenta es de España que su Rey tenga necesidad de extranjeros, como lo es de un hijo honrado ver mendigar a su padre"5.

$\mathrm{Al}$ intentar los reformistas del XVIII recuperar el control sobre el comercio peninsular y colonial, no es de extrañar que echasen la vista atrás e incluso que emplearan, casi literalmente, muchos símiles contra los extranjeros que ya fueron utilizados por los arbitristas del XVII. Sobre las cláusulas comerciales del XVIII un proyectista español denunció que eran tan desiguales "que se experimenta lugar a que las demas

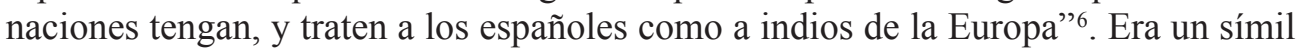
parecido al utilizado por el ya citado Moncada: "nos tratan como a indios, sacando grandes sumas de fruslerías, y juguetes, que son de gran perjuicio, por superfluas, y contra toda ley de buen gobierno, y de buen comercio". En otro proyecto se denunciaba que los extranjeros "por lo general viven en estos Reinos como de transito aunque afecten inclinacion a radicarse en ellos, siendo agentes de las fabricas de sus paises y unas esponjas o sanguijuelas que chupan los caudales del comercio para

\footnotetext{
4 Bustos Rodríguez, Manuel: «Los extranjeros y los males de España y América en los tratadistas hispanos (siglos XVI-XIX)», Trocadero, 8-9 (1996-97), pp. 47-70.

5 Moncada, Sancho de: Restauración politica de España (1619), reeditada en Madrid, Juan de Zúñiga, 1746, p. 84 .

6 Bibliothèque Nationale de France, Paris (BNPar), Fonds Français (FF), Mss. 10767, n. 6: "Memoire de Dn. Martin de Loynas pour relever differents abus dans la perception des Droits", 150-183v, 20 de septiembre de 1759.

7 Moncada: op. cit. (nota 5), p. 22.
} 
bolver a su patria cargados de ellos";; a mediados del XVII el arbitrista Martínez de Mata también se refirió a "las sanguijuelas extranjeras, que como esponjas chupan con sus sutiles modos, y política que observan a este fin, el oro y plata que es la sangre manantial del cuerpo de esta Monarquía" .

Si en los escritos de los arbitristas del XVII y de los proyectistas del XVIII las alusiones a los extranjeros tuvieron un tinte marcadamente económico, las grandes historias narrativas del XIX, con su recuperación de héroes típicamente españoles, intensificaron el desdén hacia los extranjeros. Como ocurrió en otras partes de Europa, en España la construcción del Estado liberal decimonónico puso su acento en la nación española de carácter unitario. La historia se postulaba "libre" de muchas de las pesadas cargas del antiguo régimen (las jurisdicciones señoriales, las corporaciones y los gremios, la Inquisición y los privilegios). Lo hacía también de algunas interferencias oscuras, como la de los extranjeros rapaces a la sombra de la corona e incluso de la idea de lo extranjero, esto es, de las corrientes de pensamiento llegadas desde el exterior y perturbadoras de la "auténtica" esencia española: "lo extranjero, lo austríaco, lo francés, lo importado, lo malamente traducido es el absolutismo en toda su escala gradual hasta el doctrinarismo", concluía el historiador liberal progresista Ángel Fernández de los Ríos ${ }^{10}$. Como otras naciones, España también tuvo su guerra de liberación del yugo extranjero (1808-14), en la que el extranjero y lo extranjero se habían concretizado en el francés invasor y en el afrancesado, su versión nacional. Progresistas y católico-tradicionalistas coincidieron en responsabilizar al extranjero, cada uno a su modo, de toda una serie de influencias negativas importadas que, "afortunadamente", no llegaron a inmutar el verdadero carácter del español y de lo español. Los altos ideales de la sociedad española contrastaban con el interés material del extranjero. Ferrer del Río coincidía con otros autores del XIX al describir negativamente el periodo de los Habsburgo, donde:

se hundian los vasallos en la miseria y unos tras otros se hartaban de oro los especuladores, genoveses en su mayor parte, que se prevalian de la circunstancia de abrirnos su república las puertas de Italia para monopolizar tales contratos. Así los extranjeros eran señores de la Hacienda, manejándola toda; los naturales, víctimas de un enjambre de recaudadores, que añadian lo vejatorio de la exaccion a lo insoportable del tributo; y los monarcas de dos hemisferios, dependientes de la voluntad de los asentistas, sin cuyos capitales a nada podian hacer frente ${ }^{11}$.

Menéndez Pidal (1869-1968) descendía al individuo al contrastar el interés material de Colón (en este caso genovés) con los valores de los conquistadores espa-

\footnotetext{
8 BNPar, FF, Mss. 10767, n. 1: "Projet d'une Direction generalle à Madrid pour embrasser tout le commerce d'Espagne; le tout rapporté aux Gremios', por Mateo Banquero y Manuel Antonio Gonzalo del Río, Madrid, 20 de febrero de 1753 , fos. $2-10 \mathrm{v}$.

9 Anes, Gonzalo (ed.): Memoriales y Discursos de Francisco Martínez de Mata, Madrid, Moneda y Crédito, 1971, pp. 152-3.

10 Pérez Garzón, Juan Sisinio: «Nación española y revolución liberal: la perspectiva historiográfica de los coetáneos», en Forcadell Álvarez, Carlos y Peiró Martín, Ignacio (coords.): Lecturas de la Historia: nueve reflexiones sobre historia de la historiografia, Zaragoza, Institución Fernando el Católico, 2002, pp. 23-54.

11 Ferrer del Río, Antonio: Historia del reinado de Carlos III en España, 4 tomos (Madrid, 1856), 1, p. 45.
} 
ñoles ${ }^{12}$. En suma, frente a la la edad de oro de los Reyes Católicos, los extranjeros formaban parte de un pasado en el que se aprovecharon de las debilidades de los Austrias para medrar y enriquecerse, hasta convertir al siglo XVIII (de la mano de otra dinastía extranjera), en uno de los periodos más "extranjerizantes" de la historia española. El más claro al referirse a esta centuria fue Menéndez Pelayo (1856-1912):

¡Jamás vinieron sobre nuestra raza mayores afrentas! Generales extranjeros guiaban siempre nuestros ejércitos, y una plaga de aventureros, arbitristas, abates, cortesanas y lacayos franceses, irlandeses e italianos caían sobre España, como nube de langosta, para acabarnos de saquear y empobrecer en son de reformar nuestra Hacienda y de civilizarnos ${ }^{13}$.

Pero si los extranjeros resultaban incómodos para una narrativa nacional en construcción, no lo fueron de menos para los países que los "exportaron". Por su pasada vinculación a la Monarquía, los casos de Italia y Bélgica resultan paradigmáticos. El Risorgimento italiano, como fenómeno de liberación de la presencia extranjera, no animó precisamente al estudio de los extranjeros que habían servido a otras potencias europeas. I promessi sposi, la novela histórica ambientada durante la "ocupación" española de Lombardía entre 1628 y 1630, entró a partir de su publicación en el "Libro de la patria" de la joven nación italiana y convertirse en lectura obligada en la escuela ${ }^{14}$. Los estereotipos anti-españoles presentes en la obra se vieron reflejados en la historiografía del Risorgimento, que no mostró demasiado interés en el estudio de la posición de los distintos territorios italianos en el sistema imperial hispano. Por ser Génova una de las repúblicas más vinculadas a la Monarquía, el antispagnolismo ligur resultó en su día uno de los más intresantes ${ }^{15}$. Nada de extrañar si un personaje "híbrido" como el genovés Ambrogio Spinola Doria (1569-1630), maestre de campo general del ejército de Flandes, lugarteniente general del archiduque Alberto y superintendente de Hacienda, entre otros cargos, haya resultado algo incómodo, por diferentes razones, a la historiografía italiana, belga y española ${ }^{16}$. Sólo recientemente

\footnotetext{
12 "Un extranjero, Colón, sin dejarse llevar de ningún entusiasmo por su empresa, la posterga entre dificultosas e interminables negociaciones, no admitiendo sino una magnífica serie de ganancias y recompensas, antes de arriesgarse; mientras multitud de exploradores españoles se arrojan a los más peligrosos e inauditos trabajos por una muy eventual esperanza o por el simple atractivo de la aventura, con menosprecio de toda ventaja material": Menéndez Pidal, Ramón: Los españoles en la Historia, Madrid, Espasa Calpe, 1991 (ed. original 1945), p. 85.

13 Menéndez Pelayo, Marcelino: Historia de los heterodoxos españoles, Alicante, Biblioteca Virtual Miguel de Cervantes, 2003, Libro VI, cap. 1, p. 338

14 Manzoni, Alessandro: I promessi sposi (1827, versión definitiva 1840-41).

15 Bitossi, C.: «Lo strano caso dell'antispagnolismo genovese», en Musi, A. (ed.): Alle origini di una nazione: Antispagnolismo e identità italiana, Milán, 2003, pp. 135-160.

16 No contamos con una reciente biografía sobre este importante personaje, excepto los trabajos ya clásicos de LefĖvre: Spínola et la Belgique (1601-1627), Bruselas, 1947 y Rodríguez Villa, A.: Ambrosio Spínola, primer marqués de los Balbases. Ensayo biográfico, Madrid, 1904. A Spínola no se le ha dedicado ningún monumento público en estos tres países, aunque la fortuna de ser retratado por Velázquez en La rendición de Breda le ha hecho pasar a la historia de una manera más original que otros condottieri: ColOMER, José Luis: «Ambrosio Spinola. Fortuna iconográfica de un genovés al servicio de la Monarquía», en España y Génova. Obras, artistas y coleccionistas. Los trabajos sobre el ejército de Flandes de Esteban Estríngana, Alicia: Guerra y finanzas en los Países Bajos Católicos. De Farnesio a Spínola (1592-1630), Madrid, 2002, y otros sobre distintos miembros de la familia Spínola, están ayudando a reequilibrar la situación: Álvarez-Ossorio Alvariño, Antonio: «¿El final de la Sicilia española? Fidelidad, familia y venalidad bajo el virrey marqués de los Balbases (1707-1713)», en Álvarez-Ossorio, A., GARcía,
} 
se ha llamado la atención sobre este vacío historiográfico y vienen apareciendo importantes contribuciones sobre el tema ${ }^{17}$.

Volviendo a España, la dictadura del general Franco (1939-75) cerró cualquier posibilidad de una óptica multinacional de la Monarquía. La base del Imperio se situó en Castilla y sus hombres, idealizando sobre todo el reinado de los Reyes Católicos. Se tuvo que esperar a la publicación del libro del profesor Domínguez Ortiz, Los extranjeros en la vida española durante el siglo XVII (1960) para que se llamase la atención sobre el vacío en el estudio de estas comunidades. Sin embargo, el guante lanzado por este profesor no fue recogido -salvo notables excepciones-, como lo prueba la reedición de esta misma obra en la década de los $90^{18}$. Lo que sí tuvo un incipiente desarrollo a partir de los 60 fueron los estudios que, desde el punto de vista jurídico, hacían referencia a la evolución normativa de la legislación sobre extranjeros en España desde fines de la baja Edad Media, de tal forma que los estudios en torno al peculiar "fuero de extranjería" hispano constituyen una línea que llega hasta nuestros días ${ }^{19}$.

Con la llegada de la democracia en los años 70, las universidades españolas reaccionaron contra el abuso ideológico de la "Historia imperial". El nuevo estado autonómico reivindicó el papel de la periferia frente al centralismo y muchas de las nuevas universidades se orientaron hacia una historia local o a lo sumo regional que hizo difícil el estudio (sobre bases científicas no ideológicas), del "sistema español" durante la edad moderna. Influenciadas por los Anales (y en general por la influencia de lo regional en los estudios de los historiadores franceses de la década de los 60 y 70), la fuerte impronta local también estuvo muy presente en las aproximaciones a las comunidades extranjeras, sobre todo en relación al comercio, como tendremos ocasión de apuntar después.

La crisis de la historia económica y el desarrollo de la historia social entre los años 80 y 90 del siglo XX (así como las influencias de las corrientes historiográficas a ella asociadas, como la microhistoria italiana) incrementaron el interés en España sobre grupos y minorías sociales. La expulsión de los judíos en 1492, de los moriscos en 1609 , los intentos contra la minoría gitana a lo largo del XVIII y la expulsión de los

Bernardo y León, V. (eds.), La pérdida de Europa. La Guerra de Sucesión por la Monarquía de España, Madrid, 2007, pp. 831-912.

17 El primer número de la revista Guerra e pace in età moderna: Annali di storia militare europea (Franco Angeli, 2008) fue dedicado a este tema bajo el título "Italiani al servizio straniero in età moderna" (ed. por Paola Bianchi, Davide Maffi, Enrico Stumpo). En la introducción se deja claro cómo "Il tema dei militari italiani che prestarono i loro servizi all'estero, nell'ambito dei numerosi eserciti delle piccole e grandi nazioni europee, fra Quattro e Settecento, non è mai stato seriamente affrontato dalla storiografia italiana", p. 9.

18 Domínguez Ortiz, Antonio: Los extranjeros en la vida española durante el siglo XVII y otros artículos, Sevilla, Diputación de Sevilla, 1996. Entre las excepciones aludidas, ver ViñAs Y MeY, Carmelo, Forasteros y extranjeros en el Madrid de los Austrias, Madrid, Universidad de Madrid-Ayuntamiento de Madrid, 1963 y Herrero García, Miguel, Ideas de los españoles del siglo XVII, Madrid, Gredos, 1966.

19 Bonet Correa, José: «Los extranjeros en el ordenamiento jurídico español», Revista general de legislación y jurisprudencia, 1:31 (1965); PeCOURT GARCíA, Enrique, «Una institución singular en la historia del derecho internacional privado español: el "fuero de extanjería"», en Estudios de derecho internacional público y privado. Homenaje al prof. Luis Sela Sampil, Oviedo, Universidad de Oviedo, 1970, vol. II, pp. 883-904; Álvarez y VALDÉs, Manuel: La extranjería en la historia del derecho español, Oviedo, Universidad de Oviedo, 1992; EsPINAR VICENTE, José María: La nacionalidad y la extranjería en el sistema jurídico español, Madrid, Civitas, 1994; GonZÁLEZ Beltrán, J.M., «Legislación sobre extranjeros a finales del siglo XVIII», Trocadero, 8-9 (1996-97). 
jesuitas en 1769 cuentan ya con una bibliografía abundante. El extraordinario impulso de los estudios relacionados con la Inquisición, las numerosas obras al amparo de la conmemoración de la figura de Carlos III y la más reciente conmemoración de los 400 años de la expulsión de los moriscos, han hecho que los temas sobre judíos, moriscos y jesuitas tengan todavía un papel relevante en la historiografía modernista española. Las Actas de la IV Reunión Científica de la Asociación Española de Historia Moderna, dedicadas a Disidencias y exilios en la España moderna, dan una idea de lo que estamos diciendo. Para los siglos XVI y XVII diez contribuciones estuvieron relacionadas con la Inquisición y la represión de la disidencia religiosa, otras diez con la minoría morisca, cinco con la judeo-conversa, tres presentaban una temática mixta, una estaba relacionada con la minoría gitana y una con los protestantes. Tan sólo una estuvo dedicada a una inmigración europea ${ }^{20}$; en la parte dedicada en este volumen a los estudios sobre el XVIII, fueron doce las contribuciones relacionadas con la expulsión y exilio de los jesuitas, cinco con la disicencia y exilio austracista, cuatro estuvieron dedicadas a distintos temas y tan sólo una a la expulsión de los franceses tras la guerra de la Independencia ${ }^{21}$. Se perfilaba así una fuerte presencia del componente religioso en el estudio sobre disidencias y expulsiones, con el ya característico componente local presente en muchas contribuciones.

La llegada masiva de extranjeros a España desde la década de 1990 -una de las transformaciones sociales más importantes desde la democracia- hizo que las instituciones públicas apoyaran la celebración de congresos y la edición de actas y monográficos relacionados con la inmigración. España era uno de los últimos países occidentales que se incorporaba al fenómeno inmigratorio y los historiadores gallegos -siendo Galicia una región emigrante por excelencia- fueron los primeros en reconocer la importancia de los movimientos internos y de media distancia, poco estudiados en comparación con las migraciones transoceánicas. Un primer paso importante fue la celebración en 1993 de la I Conferencia Europea sobre Migraciones Internas, coordinada por el profesor Eiras Roel ${ }^{22}$. Estos esfuerzos se vieron ampliados con las sucesivas reuniones de la Cátedra UNESCO 226 sobre Migraciones, creada en la Universidad de Santiago desde $1996^{23}$. Sin embargo, no fue hasta 2002 cuando se celebró en Málaga el primer coloquio internacional específico dedicado a Los Extranjeros en la España Moderna. Sus resultados fueron

20 Rey Castelao, Ofelia, «Exiliados irlandeses en Galicia de fines del XVI a mediados del XVII», en Mestre Sanchís, Antonio, Fernández Albadalejo, Pablo y Giménez López, Enrique (eds.): Disidencias y exilios en la España moderna, Alicante, Caja de Ahorros del Mediterráneo-Universidad de Alicante-A.E.H.M., 1997, vol. 2, pp. 99-116.

${ }^{21}$ Jarque Martínez, Encarna y Salas Auséns, José Antonio, «El último exilio de la Edad Moderna: la expulsión de los franceses al final de la guerra de Independencia», en ibidem, pp. 783-800.

22 Eiras Roel, Antonio y Rey Castelao, Ofelia (eds.): Migraciones internas y medium-distance en la Península Ibérica, Santiago, Xunta de Galicia, 1994. En este mismo año se publicó el trabajo de Bello León, Juan Manuel, Extranjeros en Castilla (1474-1501): notas y documentos para el estudio de su presencia en el reino a fines del siglo $X V$, La Laguna, Instituto de Estudios Hispánicos de Canarias, 1994.

23 Las actas de las tres reuniones fueron editadas por Eiras Roel, A. y GonzÁlez Lopo, Domingo L.: Movilidad y migraciones internas en la Europa Latina, Santiago, Servicio de Publicaciones de la Universidad, 2002; Movilidad interna y migraciones intraeuropeas en la Península Ibérica, Santiago, Universidad, 2002; La inmigración en España: Actas del Coloquio, Cátedra UNESCO 226 sobre Migracións. Santiago, Universidad, 2004. Ver http:// www.usc.es/catedras/migracs [consulta: 18 junio 2010]. 
recogidos en dos volúmenes de más de 700 páginas cada uno y 112 contribuciones en total, lo que ya indicaba de por sí el interés suscitado por el tema y su potenciali$\mathrm{dad}^{24}$. Aunque muchas de estas contribuciones se limitaban al estudio de una determinada comunidad en función de su presencia en una localidad específica, algunas de las contribuciones adelantaban estudios posteriores de carácter más global.

El tema de los extranjeros siguió apareciendo transversalmente en los estudios sobre minorías y migraciones, como lo hizo en 2002 para el caso del Mediterráneo ${ }^{25}$ o en 2003 en las XV Jornadas de Estudios Históricos del Dpto. de Historia Medieval, Moderna y Contemporánea de Salamanca ${ }^{26}$. Estas contribuciones se vieron enriquecidas con la publicación a partir de entonces de monografías sobre el tema. Dos de ellas, aparecidas en 2003, tuvieron una gran repercusión. En un polémico libro el hispanista Henry Kamen lanzó interesantes preguntas sobre el papel de los extranjeros en el sostenimiento de la Monarquía a nivel global ${ }^{27}$. Esta obra coincidió con la publicación de Defining nations: Immigrants and Citizens in Early Modern Spain and Spanish America, de Tamar Herzog, un libro que se convirtió muy pronto en referencia obligada sobre el tema. Esta profesora sugirió que muchos extranjeros eran ya reconocidos implícitamente como integrantes de una comunidad de vecinos, al residir permanentemente en ella y compartir derechos y obligaciones, sin necesidad por tanto de un reconocimiento formal y legal de la condición de vecino por parte de las autoridades en forma de cartas de naturaleza u otros instrumentos formales. La inclusión de un extranjero formaba parte, pues, de un proceso orgánico, dinámico, ejercido dentro de la propia comunidad local (vecindad) o comunidad del reino (naturaleza), más que algo dependiente del derecho en sí mismo para formalizar ambas situaciones ${ }^{28}$.

Finalmente, cabe destacar la publicación en 2004 de La Monarquía de las naciones -que recogía valiosas contribuciones sobre el tema para los siglos XVI y $\mathrm{XVII}^{29}$, y la importancia de la mujer de origen extranjero puesta de relevancia a raíz del extraordinario desarrollo de los estudios de género y vida cotidiana ${ }^{30}$. Para el siglo XVIII las fuentes conservadas apuntan a un alto grado de alfabetización de las esposas de comerciantes de origen extranjero, como lo prueba el hecho de que en Alicante muchas de ellas se encargaron de administrar directamente los bienes y las compañías de negocios de sus esposos de origen francés expulsados de España

\footnotetext{
${ }^{24}$ Villar García, Ma Begoña y Pezzi Cristóbal, Pilar (eds.): Los Extranjeros en la España Moderna: actas del I Coloquio Internacional, celebrado en Málaga del 28 al 30 de noviembre de 2002, 2 vols. Málaga, Ministerio de Ciencia y Tecnología, 2003.

${ }_{25}$ Pimentel, M.: Mediterráneo económico, 1. Colección Estudios Socioeconómicos. Procesos migratorios, economía y personas, Almería, Instituto Cajamar, 2002.

26 Intervenciones que fueron recogidas en: VACA LoREnzo, Ángel et al.: Minorías y migraciones en la historia, Salamanca, Ediciones Universidad de Salamanca, 2004.

27 KAMEN, Henry: Imperio: la forja de España como potencia mundial, Madrid, Aguilar, 2003.

28 Herzog, Tamar: Vecinos y extranjeros: hacerse español en la edad moderna, Madrid, Alianza, 2006.

29 Álvarez-Ossorio, Antonio y García García, Bernardo (eds.): La Monarquía de las naciones. Patria, nación y naturaleza en la Monarquía de España, Madrid, Fundación Carlos de Amberes, 2004.

30 Hernández Borge, Julio y GonzÁlez Lopo, Domingo L. (eds.): Mujer y emigración: una perspectiva plural. Cátedra UNESCO 226 sobre Migraciones: Actas del Coloquio Internacional 23-24 de noviembre de 2006, Santiago, Universidad de Santiago, 2008.
} 
en 1793 , lo que permitió en muchos casos la continuidad del negocio ${ }^{31}$. Su papel como agentes activos de la Ilustración también es evidente en el caso de Inés Joyes estudiado por Bolufer Peruga ${ }^{32}$.

En estos momentos es el estudio teórico de los diferentes modelos de naciones y sus redes sociales lo que acapara una gran atención. El término "modelo", como sinónimo de arquetipo, patrón, exige todas las precauciones que cualquier caracterización exclusivista como "extranjeros" hemos señalado en la introducción de este número. No supone una "ghetización" de un grupo en concreto, sino el estudio posible de sus pautas de comportamiento, a nivel individual y grupal, con respecto a la administración y sociedad de acogida. Es decir, en un marco más amplio donde están presentes los elementos que son también característicos a los grupos de la sociedad del antiguo régimen, tratar de identificar los elementos que pueden ser representativos de cada modelo. Esta diferenciación era clave para una comunidad determinada, en un marco de fuerte competencia en la atracción de patronazgo. El ejemplo utilizado por Eleonora Poggio en este monográfico resulta ilustrativo en este sentido: las órdenes para llevar a cabo la composición de extranjeros ordenada desde Madrid en 1592 no se llevaron a cabo en México hasta 1595, porque los oidores de la Audiencia no entendían cómo proceder con "una iniciativa que parecía no contemplar diferencias entre las distintas naciones o en las relaciones que cada una de ellas mantenía con el monarca". Por razones de espacio sólo nos referiremos a dos de estos elementos transversales más importantes de las naciones -nobleza y religión-, para pasar a recoger las aportaciones más relevantes para los modelos de nación mejor estudiados hasta hoy.

El primero de estos elementos definitorios, transversal a la sociedad del antiguo régimen y a los extranjeros, fue el importante papel de la nobleza. Muchos extranjeros alcanzaron posiciones claves en la Monarquía porque ellos mismos o su familia pertenecían a este grupo en sus países de origen. La conformación una "internacional de la nobleza" entre distintos territorios de la Monarquía -ese ydeal typus nobiliario que está calando cada vez más en la historiografía modernistapuede explicar la relativa facilidad de integración de sus individuos. Esta extraordinaria importancia alcanzada por los extranjeros en el seno de la nobleza española ha sido señalada recientemente por Soria Mesa en su estudio general sobre la nobleza. En unas páginas dedicadas a genoveses y portugueses, este autor ha llamado la atención sobre la capacidad de inserción del grupo ligur en los poderes locales ${ }^{33}$. La necesidad de abordar el estudio de las élites nobiliarias europeas desde una perspectiva transnacional también ha quedado de manifiesto en el trabajo coordinado por Yun Casalilla. En varias de las contribuciones recogidas en este volumen se insiste en el "capital transnacional", esto es, el valor íntrinseco del propio cosmopolitismo de muchos de estos individuos y sus redes familiares, de gran interés para

\footnotetext{
31 Álvarez Cañas, Ma . Luisa: «El protagonismo de la mujer de la colonia francesa de Alicante. La defensa de sus intereses patrimoniales en un periodo de crisis (1793-1795)», Nuevo Mundo, Mundos Nuevos Coloquios (2008) [http://nuevomundo.revues.org/29633, consulta 01/12/2010].

32 Bolufer Peruga, M.: La vida y la escritura en el siglo XVIII: Inés Joyes: Apología de las mujeres, Valencia, Universidad de Valencia, 2008.

33 Soria Mesa, Enrique: La nobleza en la España moderna. Cambio y continuidad, Madrid, Marcial Pons, 2007, p. 89.
} 
el funcionamiento de una monarquía tan compleja y geográficamente tan dispersa como la española ${ }^{34}$.

El segundo de los elementos transversales, el factor religioso, fue utilizado como elemento diferenciador positivo o discriminatorio hacia los extranjeros. En el catálogo del Tribunal de la Corte se incluyen los procesos llevados a cabo bajo 20 delitos distintos aplicados a españoles y a otras 24 nacionalidades, europeos en su mayor parte ${ }^{35}$. Los sistemas de defensa de los extranjeros también están recibiendo una gran atención. Un reciente trabajo ha puesto de manifiesto que, aparte de las conocidas dificultades del escribano de turno para transcribir un nombre extranjero, también existían intereses por parte de los propios extranjeros para utilizar un nombre u otro, en según qué contexto geográfico ${ }^{36}$.

Además de compartir características comunes con otros grupos de extranjeros y con la sociedad española del antiguo régimen en general, los individuos utilizaban instrumentos propios de cada grupo. El "modelo genovés" presenta algunas características que facilitó su ennoblecimiento y ascenso social. Además de su catolicismo, este grupo presentaba un perfil indudablemente aristocrático, corroborado por el privilegio de la élite oligárquica de la República desde $1528^{37}$. La acreditada pureza de sangre genovesa, tan importante de cara a la obtención de un hábito militar, no estaba tan clara para los irlandeses. Éstos también se declaraban "limpios" de sangre, pero el complicadísimo universo étnico-religioso insular, su división política y la falta de pruebas escritas hicieron que la administración española dudase sobre determinados perfiles $^{38}$. Lo que para los genoveses podría haber resultado un problema (su reputada actividad financiero-comercial y legendaria riqueza en el imaginario colectivo de la sociedad castellana ${ }^{39}$ ) fue resuelto insistiendo en su acreditada aristocracia; al contrario, el grupo irlandés insistió en su dedicación exclusiva al oficio de las armas

34 Yun Casalilla, Bartolomé (dir.): Las Redes del Imperio. Élites sociales en la articulación de la Monarquía hispánica, 1492-1714, Madrid, Marcial Pons, 2009. En esta línea ver también Guillén Berrendero, José Antonio: «Otros territorios, mismos discursos. La formación de una idea de nobleza transnacional en los territorios italianos de la Monarquía española: tres ejemplos», en Martínez Millán, José y Rivero Rodríguez, Manuel (coords.): Centros de poder italianos en la Monarquía Hispánica (siglos XV-XVIII), Madrid, Polifemo, 2010, vol. 2, pp. 1311-1336.

35 Blázquez Miguel, Juan: «Catálogo de procesos inquisitoriales del Tribunal de Corte», Revista de la Inquisición, 3 (1994), 205-57. Entre los delitos, los más abundantes son los llevados a cabo por criptojudaísmo y luteranismo. Como era previsible, en el primero abundan los portugueses, mientras que en el segundo las nacionalidades son variadas, afectando sobre todo a países del norte y centroeuropeos. En Madrid, entre 1650 y 1820, la Inquisición juzgó a cerca de un millar de extranjeros (954), de los cuales 219 eran alemanes, 214 portugueses, 119 franceses, 104 ingleses, 78 suizos, 61 irlandeses, 54 italianos y el resto de otras naciones: BlázQuez Miguel, J.: Madrid: judios, herejes y brujas. El tribunal de la Corte (1650-1820), 1990, pp 70-7. Para una visión más amplia ver: THOMAs, Werner, Los protestantes y la Inquisición en España en tiempos de Reforma y Contrarreforma, Lovaina, University Press, 2001.

36 SAlinero, Gregorio y Testón NúÑEZ, Isabel (eds.): Un juego de engaños: movilidad, nombres y apellidos en los siglos XV a XVIII, Madrid, Casa de Velázquez, 2010.

37 Herrero Sánchez, Manuel: «La red genovesa Spínola y en entramado transnacional de los marqueses de los Balbases al servicio de la Monarquía Hispánica», en Yun CASAlilla: op. cit. (nota 34), p. 105. Sobre esta comunidad resulta fundamental: Herrero Sánchez, Ben Yessef Garfia, Yasmina Rocío, Bitossi, Carlo y Puncuh, Dino (eds.), Génova y la Monarquía Hispánica (1528-1713), Génova, Atti della Società Ligure di Storia Patria, 2011, 2 vols.

38 Sobre estos problemas ver Recio Morales, Óscar: Ireland and the Spanish Empire 1600-1825, Dublín, Four Courts Press, 2010, pp. 76-85.

39 GiRón Pascual, Rafael María: «Ricos, nobles y poderosos: la imagen de los mercaderes genoveses del Reino de Granada en la Edad Moderna», en Historia y Genealogía, 1 (2011), pp. 41-56. 
para acreditar su nobleza y denunció a otros grupos competidores de la propia isla dedicados al comercio. La importancia de la neutralidad y menor visibilidad también ha sido recientemente puesto en evidencia con respecto a la comunidad genovesa del XVIII. A pesar de no contar con una potencia marítimo-militar paragonable a la de Gran Bretaña o Francia, precisamente esta debilidad les permitió moverse por distintos escenarios de la Monarquía hispánica sin representar una amenaza, al tiempo que se protegían ante la sociedad de acogida solicitando cartas de naturaleza ${ }^{40}$.

Por su parte, Crespo Solana ha señalado que las divisiones político-religiosas entre Flandes y las Provincias Unidas no impidieron "la formación de una identidad colectiva en el exilio", es decir, un discurso específico de estas dos comunidades aplicado a un espacio geográfico determinado ${ }^{41}$. La maleabilidad de los discursos identitarios, incluso al interno de una misma comunidad, presentaba características todavía más acusadas en los territorios de frontera, donde la relación con otras comunidades étnico-lingüísticas y religiosas formaba parte de la cotidianidad y donde era posible que la administración no dispusiese de los recursos suficientes para implantar un modelo social más homogéneo ${ }^{42}$.

Teniendo en cuenta esta complejidad, en estos momentos podemos decir que el modelo francés, el flamenco-neerlandés, el irlandés y el genovés son los mejor estudiados. La importancia del estudio sobre la inmigración francesa en España ha estado relacionado con la extraordinaria relevancia del hispanismo francés ${ }^{43}$. Nos encontramos ante el modelo mejor estudiado. Dado el elevado número de inmigrantes franceses, las imagenes populares sobre esta nación son ya muy abundantes desde la literatura del Siglo de Oro ${ }^{44}$. A diferencia de otros modelos, los estudios sobre las regiones de origen de la emigración son abundantes y de calidad ${ }^{45}$. Los trabajos del profesor Ozanam -especialmente sus contribuciones a la colonia mercantil de Cádiz ${ }^{46}$ - funcionaron como un auténtico impulso de futuras investiga-

40 Brilli, Catia: «Mercaderes genoveses en el Cádiz del siglo XVIII. Crisis y reajuste de una simbiosis secular», en Crespo Solana, Ana (coord.): Comunidades transnacionales: colonias de mercaderes extranjeros en el Mundo Atlántico (1500-1800), Madrid, Ediciones Doce Calles, 2010, pp. 83-102.

${ }_{41}$ Crespo Solana, Ana: «Comunidad y familia versus nación en el marco atlántico: cooperación y competencia en las redes de negociantes flamencos (1690-1760)», en CRESPO SolANA: op. cit. (nota 40), p. 52.

42 Caso de la frontera sur de los actuales Estados Unidos durante el XVIII: Allen Smith, Gene y Hilton, Sylvia L. (eds.): Nexus of Empire: Negotiating Loyalty and Identity in the Revolutionary Borderlands, 1760s-1820s, Gainesville, FL, University of Florida, 2010.

43 La contribución más reciente sobre el tema puede encontrarse en GARCía GonZÁLEz, F.: La historia moderna de España y el hispanismo francés, Madrid, Marcial Pons, 2009.

44 Manero Sorolla, Ma . Pilar: «Imágenes de Francia en la novela picaresca española», en Lafarga, Francisco (ed.): Imágenes de Francia en las letras hispánicas, Barcelona, PPU, 1989, pp. 427-435; GutiérREZ, Asensio, La France et les Français dans la litterature espagnole. Un aspect de la Xénofobie en Espagne (1598-1665), Publications de l'Université de Saint-Etienne, 1977.

45 Sirva como ejemplo el trabajo sobre los espagnols (emigrantes franceses de Auvernia y Limousin) de Poitrineau, A.: Les espagnols de l'Auvergne et du Limousin du XVIIème au XIXéme Siècle, Aurillac, Malroux-Mazel Libraire-Editeur, 1985; sobre la región de Auvernia, ver tambén los trabajos de Duroux, Rose: Les Auvergnats de Castille. Renaissance et mort d'une migration au XIXe siècle, Clermont Ferrand, Association des Publications de la Faculté des Lettres, 1992 y una aproximación, de la misma autora, en «España país tradicional de inmigración. Los auverneses de Castilla y sus fuentes», en Migraciones \& Exilios: Cuadernos de la Asociación para el estudio de los exilios y migraciones ibéricos contemporáneos, 1 (2000), pp. 97-127.

46 Ozanam, Didier: «La colonie française de Cadix au XVIII siècle», Mélanges de la Casa de Velázquez, t. 4 (1968), pp. 259368 y «Le théâtre français de Cadix au XVIII siècle (1769-1779)», en Mélanges de la Casa de Velazquez, 10 (1974), pp. $203-231$. 
ciones. Hasta la fecha podemos contar con, al menos, 89 libros y artículos donde aparece específicamente la referencia a la emigración francesa, destacando sobre todo los estudios dedicados al comercio ${ }^{47}$. Los pioneros trabajos de Girard sobre el comercio francés en Sevilla y Cádiz ${ }^{48}$ y los de Nadal y Giralt sobre la inmigración francesa en Cataluña ${ }^{49}$ fueron extendiéndose al resto de regiones peninsulares, especialmente con los trabajos de Salas Auséns y de Langé sobre Aragón ${ }^{50}$, los de Poitrineau sobre Valencia ${ }^{51}$ y Villar sobre Málaga ${ }^{52}$. Esta regionalización dio paso a una miriada de estudios sobre determinadas comarcas, ciudades y ámbitos rurales ${ }^{53}$. De entre todos ellos, la corte ${ }^{54} \mathrm{y}$ muy especialmente la ciudad de Cádiz, han recibido una gran atención ${ }^{55}$. A este punto, son de agradecer las síntesis de Amalric $^{56}$ y la reciente monografía de Salas Auséns ${ }^{57}$.

Sobre las naciones flamenca y holandesa, el interés también ha estado centrado prevalentemente en el ámbito comercial, gracias en buena parte a los trabajos de Crespo Solana. La bibliografía generada durante los últimos años sobre el "modelo" irlandés también resulta una de las más abundantes ${ }^{58}$. Por último, la reciente publicación de Centros de poder italianos en la Monarquía Hispánica (56 contri-

47 Entre los que destacamos el trabajo de Zylberberg, Michel: Une si douce domination. Les milieux d'affaires français et l'Espagne vers 1780-1808, París, Comité por l'histoire économique et financière de la France, 1993.

48 Girard, Albert: Le commerce français à Séville et à Cádiz au temps des Habsbourg: Contribution à l'étude du commerce étranger en Espagne au XVI et XVIII siècles, París, E. de Boccard, 1932.

49 Nadal, J. y GiRALt, E.: La population catalane de 1553 à 1717. L'inmigration française et les autres facteurs de son developpement, París, SEVPEN, 1960.

50 Salas Auséns, José Antonio: «La inmigración francesa en Aragón en la Edad Moderna», en Estudios del Departamento de Historia Moderna de Zaragoza (1986), pp. 51-78; LANGÉ, Ch.: La inmigración francesa en Aragón (Siglo XVI y primera mitad del XVII), Zaragoza, Institución Fernando el Católico, 1993.

51 Poitrineau, A.: «La inmigración francesa en el Reino de Valencia (siglos XVI-XIX)», Moneda y Crédito, 137 (1976), pp. 103-132.

52 Villar García, M Begoña: Los extranjeros en Málaga en el siglo XVIII, Córdoba, Monte de Piedad y Caja de Ahorros de Córdoba, 1982.

53 SAlas AusÉns: «Buscando vivir en la ciudad: trayectorias de inmigrantes franceses en los siglos XVII y XVIII», Revista de Demografia Histórica, XXI, I (2003), pp. 141-165; Moreu-ReY: Els inmigrants francesos a Barcelona (ss. XVI-XVIII), Barcelona, 1950; PÉrez Hervás, y PÉrez OrTIZ: «Estructura familiar y condición social de la población francesa en Murcia (siglo XVIII)», Familia, casa y trabajo, Murcia, 1997, pp. 297-311; PonSOT, P.: «Les françaises a Cordove en 1791-1793», Melanges de la Casa de Velázquez, XV (1979), pp. 503-507.

54 Alcouffe, D.: «Contribution à la connaissance des emigrés français de Madrid au XVIIe siècle», en Mélanges de la Casa de Velazquez, vol. II (1966), pp. 179-197; OzAnAM: «Les français à Madrid dans la deuxième moitié du XVIIIe siècle», en Madrazo, Santos y Pinto, Virgilio (eds.): Madrid en la época moderna: espacio, sociedad y cultura, Madrid, UAM y Casa de Velázquez, 1991, pp. 177-199.

55 Enciso Recio, Luis Miguel: «Actividades de los franceses en Cádiz, 1789-1790», Hispania, XIX (1959), pp. 251-286; García Baquero, A. y Collado, P.: «Les Français a Cadiz au XVIIIe siècle», en Les Français en Espagne à l'époque moderne (XVIe-XVIIle siècles), París, C.N.R.S., 1990, pp. 173-196.

56 Amalric, J.P.: «Les migrations françaises en Espagne à l’époque moderne», en Eiras RoEl, A. y Rey CASTELAO, Ofelia (eds.): Les migrations internes et à moyenne distance en Europe, 1500-1900, vol. I, Santiago, 1994, pp. 413430 y «Franceses en tierras de España: una presencia mediadora en el Antiguo Régimen», en Villar y PezzI: op. cit. (nota 24), vol. I, pp. 23-38.

57 Salas AusÉns, José Antonio: En busca de El Dorado: inmigración francesa en la España de la Edad Moderna, Bilbao, Servicio Editorial de la Universidad del País Vasco, 2010.

${ }^{58}$ Como obras generales puede recurrirse a GARCía Hernán, Enrique et. al. (eds.): Irlanda y la Monarquía hispánica, Madrid, CSIC-Universidad de Alcalá, 2002; Downey, Declan y CresPo, J. (eds.): Spanish-Irish relations through the ages, Dublín, Four Courts Press, 2008; VILlar, M.B. (ed.): La emigración irlandesa en el siglo XVIII, Málaga, 2000. 
buciones en más de 2.000 páginas $)^{59}$ ha supuesto un importante paso, ya que hasta este momento era el comercio y las finanzas los campos predilectos y la genovesa la comunidad mejor estudiada con diferencia ${ }^{60}$. De hecho para esta nación contamos con varios proyectos de investigación en curso y trabajos de excelente nivel, tanto de la historiografía italiana ${ }^{61}$ como de la española ${ }^{62}$.

\section{2. ÁMBITOS PROFESIONALES}

Finanzas y comercio han sido los ámbitos profesionales más estudiados sobre los extranjeros. Desde la llegada al trono de los Habsburgo ya existía una corriente crítica sobre su papel en las finanzas. El permanente déficit financiero de la dinastía y sus bancarrotas fueron achacadas a la voracidad de los prestamistas extranjeros. Este importante papel ha tenido su reflejo en una bibliografía más equilibrada desde la publicación del trascendental estudio de Ramón Carande, Carlos V y sus banqueros (orig. en 3 vols: 1943, 1949 y 1967). La "voracidad" de estos financieros también ha sido redimensionada con aportaciones como las de Boyajian, Broens o Schreiber sobre las redes financieras portuguesas y sus banqueros en Madrid ${ }^{63}$, de Sanz Ayán sobre los financieros de origen holandés ${ }^{64} \mathrm{o}$ las de Maixé-Altés sobre el importante papel de la colonia genovesa en la expansión económica catalana del $\mathrm{XVIII}^{65}$. Como se ha puesto de relevancia para los genoveses, el dinero ayuda pero

59 Martínez Millán y Rivero Rodríguez: op. cit (nota 34).

60 Para el siglo XVII contamos con la contribución de Pradells NADAL, J.: «Italianos en la España del siglo XVII», en GimÉnEZ, E. y LozAno, M.A.: Españoles en Italia e Italianos en España: IV Encuentro de investigadores de las universidades de Alicante y Macerata (mayo 1995), Alicante, 1995, pp. 61-75; Melis, F.: Mercaderes italianos en España, siglos XIV-XVI. Sevilla, 1976; CANosA, R.: Banchieri genovesi e sovrani spagnoli: tra cinquecento e seicento, Roma, 1998.

${ }_{61}$ Muto, G.: «La presenza dei Genovesi nei domini spagnoli in Italia», en Puncuh, D. (ed.): Studi in memoria di Giorgio Costamagna. Atti della Società Ligure di Storia Patria, Nuova Serie XLIII (CXVIII), fasc. I, Génova, 2003, pp. 659-671; Boccardo, P., Colomer, J.L. y Di Fabio, C. (eds.), Genova e la Spagna. Opere, artisti, committenti, collezionisti, Milán, 2002.

62 Álvarez Nogal: «I genovesi e la monarchia spagnola tra Cinque e Seicento», Atti della Società Ligure di Storia Patria, Nuova Serie XLI (CXV), fasc. II, 2001, pp. 107-121; y «Las compañías bancarias genovesas en Madrid a principios del siglo XVII», Hispania, 219 (2005) pp. 67-90; SANZ AYÁn, Carmen: «Presencia y fortuna de los hombres de negocios genoveses durante la crisis hispana de 1640», Hispania, 219 (2005); Herrero SÁNCHEZ, Manuel: introducción al monográfico sobre Génova y la Monarquía Hispánica, en Hispania, 219 (2005), pp. 9-151 y el proyecto de investigación HUM2006-10206 «Una república mercantil en una Europa de príncipes: naturaleza y transformaciones del agregado hispanogenovés, 1528-1700»: www.genovamonarquiahispanica.org

63 Boyajian, J.C.: Portuguese bankers at the Court of Spain, 1626-1650, New Brunswick, Rutgers University Press, 1983; Broens, N.: Monarquía y capital mercantil. Felipe IV y las redes comerciales portuguesas (1627-1635), Madrid, Universidad Autónoma, 1989; Schreiber, M.: Marranen in Madrid, 1600-1700, Stuttgart, Franz Steiner, 1994.

${ }^{64}$ SAnZ AyÁn, Carmen: «Las redes financieras franco-holandesas y la lana en el tránsito del siglo XVII al XVIII», en GonzÁlez Enciso, Agustín (ed.): El negocio de la lana en España (1650-1830), Pamplona, Eunsa, 2001, pp. 77-108, «Asentistas holandeses en las finanzas de la monarquía hispánica (1680-1715)», Diálogos hispánicos de Ámsterdam, 16 (1995), pp. 139-156 y «Negociadores y capitales holandeses en los sistemas de abastecimiento de pertrechos navales de la Monarquía Hispánica durante el siglo XVII», Hispania, vol. 52, 182 (1992), pp. 915-945.

${ }_{65}$ MaiXÉ-Altés, Juan Carles: «Parentesco y relaciones sociales en el seno de la burguesía barcelonesa: los extranjeros en la Barcelona de los s. XVII y XVIII», Manuscrits, 6 (1987), pp. 151-180 y «Els genovesos a la Barcelona moderna», L'Avenç, 104 (1987), pp. 40-46. Ver también Neri, Enrica: Uomini d'affari e di goberno tra Genova e Madrid (secoli XVI-XVII), Milano, Vita e Pensiero, 1989. 
no explica toda la capacidad de esta comunidad para entablar negocios con la Monarquía. Otros factores, como el acceso a la información proporcionada por la Real Hacienda, o las posibilidades de ascenso social explican también este interés a la hora de hacer negocios con el rey ${ }^{66}$. Para en el siglo XVIII la presencia de banqueros de origen extranjero en Madrid (ahora prevalentemente franceses) ha recibido la atención de Pérez Sarrión ${ }^{67}$.

La carrera de Indias y en general el comercio peninsular de la edad moderna en España resulta hoy uno de los temas mejor estudiados, sobre todo para el XVIII ${ }^{68}$. Esto, a pesar de que, como ha señalado Bustos Rodríguez, los estudios relacionados con el grupo social dedicado al comercio en España tuvieron en su origen escasa relevancia, si se compara con el análisis de otros grupos como la nobleza y el clero, o la escasa importancia que para la gesta nacional adquiría el grupo mercantil ${ }^{69}$. Aún así, el desequilibrio entre las mejor estudiadas colonias extranjeras del XVIII y los estudios sobre los siglos XVI y XVII es evidente, así como un desequilibrio centroperiferia, a favor de los estudios de las ciudades portuarias y los menos conocidos mercados del interior. Estos desequilibrios responden a diversas causas, como la mayor abundancia de fuentes documentales (comparada con los siglos XVI y XVII), sobre todo notariales ${ }^{70}$.

Sin embargo, la rica información proporcionada por los protocolos hizo que a menudo no se pasase de la descripción local de las actividades de los comerciantes extranjeros en función de pertenecer a una nación u otra. Esto a pesar de que ya en los años 50 y 60 del siglo pasado la historiografía francesa en torno a Braudel ya advertía que la característica principal de su actividad era precisamente su internacionalidad y operatividad en red. Las fuentes también condicionaron (en parte) el desequilibrio entre los trabajos dedicados a grandes puertos comerciales e importantes familias y los más escasos estudios sobre comercio interior y pequeñas compañías ${ }^{71}$. En otros casos, el peso de la historia hizo que muchas de estas comunidades, aún siendo de

${ }^{66}$ Alonso García, David: «Una nación, diferentes familias, múltiples redes. Genoveses en Castilla a principios de la Edad Moderna», en Crespo Solana: op. cit. (nota 40), pp. 65-82.

${ }_{67}$ PÉrez SARRIÓN, G.: «Intereses financieros y nacionalismo. La pugna entre mercaderes banqueros españoles y franceses en Madrid, 1766-1796», Cuadernos de Historia Moderna, Anejos VII (2008), pp. 31-72, y «Los franceses y la crisis financiera de la Ilustración en España», Spagna Contemporanea, XIV, 27 (2005), pp. 3-26.

68 Tres trabajos imprescindibles: Lobo CABrera, Manuel y SuÁrez Grimón, Vicente (eds.): El comercio en el Antiguo Régimen, Las Palmas, Universidad, 1995; el monográfico "El comercio en la España del Antiguo Régimen”, Obradoiro de Historia Moderna, 17 (2008); Böttcher, Nikolaus, Hausberger, Bernd e Ibarra, Antonio (coords.): Redes y negocios globales en el mundo ibérico, siglos XVI-XVIII, Iberoamericana-Vervuert-El Colegio de México, 2011.

69 Bustos Rodríguez, Manuel: «La problemática acerca de los comerciantes de la Carrera de Indias», en CRESPO Solana: op. cit. (nota 40), pp. 29-45.

70 Una contribución metodológica sobre la importancia de estas fuentes en CRESPO SOLANA, Ana: «Extranjeros en la Corte: análisis de una dialéctica entre la administración borbónica y las comunidades mercantiles en España en la primera mitad del siglo XVIII», en Bravo Lozano, Jesús (ed.): Espacios de Poder. Cortes, Ciudades y Villas, Madrid, 2002, 2, pp. 345-362.

71 La historiografia se ha centrado en la "edad de oro" de ciudades mercantiles tan importantes como el Cadiz del XVIII, pero existen menos estudios sobre cómo la crisis finisecular afectó a estas comunidades: BarTolomeI, Arnaud: «Le marchand étranger face à la crise: départ ou intégration? Le cas de la colonie française de Cadix aux périodes révolutionnaire et impériale», en BurKard, Albrecht (ed.): Commerce, voyage et expérience religieuse (XVIe-XVIIIe siècles), Rennes, PUR, 2008, pp. 475-96. 
la misma nación, aparezcan desconectadas entre sí, cuando en realidad la interdependencia era uno de sus pilares básicos. Por tanto, sería más provechoso estudiar a un individuo, una familia o a una comunidad extranjera presente en un determinado territorio si la conectamos con otras realidades supra-locales: el agente comercial de la familia en otros puertos, las relaciones del individuo o de la familia con otros estamentos profesionales de importancia por los extranjeros (como el mundo militar) o con el propio discurso de nación extranjera en el que se enmarca el individuo, la familia o la comunidad extranjera objeto de estudio. En este sentido, un paso muy importante está siendo abordar su estudio desde múltiples facetas: no sólo económicas, sino también políticas, culturales, familiares, lingüísticas e identitarias. La mayor parte de los trabajos hacen referencia a una progresiva aristocratización de las familias de origen extranjero dedicadas al comercio y la asunción de parámetros típicamente hispanos como la compra de tierras y un mayor peso del aspecto rentista, en detrimento de una apuesta por la inversión de capital de riesgo ${ }^{72}$. Esto también incluyó una progresiva "militarización" de las familias, destinando a alguno de sus miembros a la oficialidad del ejército (en muchos casos gracias a la venalidad) como una estrategia de diversificación de actividades, pero también para obtener una renta segura y ascender socialmente.

Si en el caso de las finanzas y del comercio la actividad de los extranjeros fue vista tradicionalmente en términos negativos, ha sido sobre todo el olvido lo que propició un escaso interés sobre el componente extranjero en los ejércitos. Durante los siglos XVI y XVII las fuentes de la época y la literatura del Siglo de Oro presentaron al soldado de origen peninsular de los tercios como el prototipo de guerrero, gallardo y arrogante, caballero por excelencia. Las naciones no eran sino los "ayudantes inferiores del imperio europeo"73. La historiografía posterior recogió esta idealización del soldado español no sólo como el más sufrido, sino como el que no se movía-como las tropas de las otras naciones- por la paga, sino por otros ideales superiores como la fe o su fidelidad ciega al rey. En realidad, los españoles sólo eran un componente más (y en numerosas ocasiones precisamente no el más numeroso) de estas famosas unidades. En demasiadas ocasiones se han utilizado directamente las fuentes literarias de la época, no exentas de intención ${ }^{74}$.

En líneas generales podemos decir que la importante renovación de la historiografía española sobre ejército y sociedad llevada a cabo durante los últimos años no se ha visto todavía reflejada en un estudio más profundo sobre el componente

\footnotetext{
72 Este parece ser el caso por ejemplo de la familia de los Bensi en la década de 1780 estudiada por MaIXÉ-Altés: op. cit. (nota 65, 1987).

73 Un análisis sobre esta retórica en García HernÁn, David: «La visión de sí mismo del Imperio Español», en García Hernán, David: La Historia sin complejos. La nueva visión del Imperio Español (estudios en honor de John H. Elliott), Madrid, Actas, 2010, pp. 288-336.

74 Un ejemplo en el siguiente párrafo de Menéndez Pidal: “Al irse a dar la batalla de Pavía, los españoles ceden sus pagas y hasta entregan sus peculios personales a Pescara para satisfacer a las tropas auxiliares tudescas; o bien, como refiere Calderón en su comedia El sitio de Breda, los españoles ofrecen sus ganancias a los comilitones extranjeros a fin de que éstos renuncien al saqueo de la ciudad, haciendo más noble la victoria": MenÉndez PIDAL, Ramón, Los españoles en la Historia, Madrid, Espasa Calpe, 1991 (ed. original 1945), p. 84.
} 
multinacional del ejército ${ }^{75}$. Los estudios sobre las naciones irlandesa y flamenca han demostrado una relación de servicio al rey mucho más compleja que el cobro de una soldada, por lo que el calificativo de "mercenarios" resulta completamente desfasado (a no ser que se utilice de forma intencional para subrayar la importancia del componente exclusivamente "nacional") ${ }^{76}$. Sólo en el caso del modelo suizo podemos llegar a entrever esta relación meramente contractual, pero todavía no contamos con un estudio sobre este modelo. Otros, como el italiano, son mejor conocidos para los siglos XVI y XVII, pero muy poco para el XVIII ${ }^{77}$. A falta de estudios más precisos, todavía en 1768 un $28 \%$ de las tropas eran de origen extranjero, sin contar las tropas de la Guardia Real, a cuyo frente se situaban importantes familias flamencas e italianas ${ }^{78}$.

Los "extranjeros del rey" también ocuparon un lugar preponderante cerca del monarca. El ápice de su influencia llegó en el siglo XVIII, cuando políticos y militares de origen extra-peninsular alcanzaron elevadas posiciones en palacio. Aunque Felipe $\mathrm{V}$ asegurase a la ciudad de Granada su intención de servirse exclusivamente de españoles para su gobierno, la realidad fue bien distinta ${ }^{79}$. La introducción en la corte de modas y costumbres extranjeras, de la lengua francesa o de la cultura italiana se vieron favorecidas por la política matrimonial dinástica y tampoco es de extrañar que muchos de los consejeros de estos monarcas fueran "importados" directamente desde París o Nápoles. La utilización de las divisiones "nacionales" para aludir a los delicados equilibrios de poder entre las distintas facciones cortesanas ya se dio en la propia época. Dado el influyente papel de los representantes extranjeros en la corte del XVIII -apoyando a un ministro afín a los intereses de

75 Dos estudios generales en Riвot, Luis: «Las naciones en el Ejército de los Austrias», en Álvarez-Ossorio, Antonio y GARCíA GARCíA, Bernardo (eds.): La Monarquía de las naciones. Patria, nación y naturaleza en la Monarquía de España, Madrid, Fundación Carlos de Amberes, 2004, pp. 653-677 y AndúJAR CASTILlo, Francisco: «Las naciones en el ejército de los Borbones», en González CRuz, David (ed.), Extranjeros y enemigos en Iberoamérica: la visión del otro. Del Imperio español a la Guerra de la Independencia, Madrid, Sílex, 2010, pp. 137-154.

76 García Hernán, Enrique y Recio Morales, Óscar: Extranjeros en el ejército: militares irlandeses en la sociedad española, 1580-1818, Madrid, Ministerio de Defensa, 2007; sobre los flamencos: GLeSENER, Thomas: La Garde du Roi. Pouvoirs, élites et nations dans la monarchie hispanique (1700-1823), Toulouse, 2007 (Tesis Doctoral inédita); «¿Nación flamenca o élite de poder? Los militares "flamencos” en la España de los Borbones», en ÁlvAREZOssorio y GARCía GARCÍA: op. cit. (nota 75), pp. 701-719 y «Les «étrangers» du roi. La réforme des gardes royales au début du régne de Philippe V (1701-1705)», Mélanges de la Casa de Velázquez, 35-2 (2005), pp. 219-242.

77 Para el XVII: MAFFI, Davide: Il baluardo della Corona: Guerra, esercito, finanze e società nella Lombardia seicentesca (1630-1660), Firenze, Le Monnier, 2007 y su continuación en La cittadella in armi: Esercito, società e finanza nella Lombardia di Carlo II 1660-1700, Milano, FrancoAngeli, 2010. Para el XVIII: Andúsar Castillo, Francisco: «Entre la Corte y la guerra. Militares italianos al servicio de España en el siglo XVIII», Guerra e Pace in etá moderna. Annali di Storia militare europea, 1 (2008), pp. 105-134 e IrLES ViCENTE, María del Carmen: «Italianos en la administración territorial española del siglo XVIII», Revista de Historia Moderna. Anales de la Universidad de Alicante, 16 (1997), pp. 157-176.

78 Vicente del Rey, Enrique, Reseña orgánica de la Infantería Española desde la promulgación de las vigentes ordenanzas hasta nuestros días, Madrid, Dirección General de Infantería, 1879, I, pp. 17-18.

79 "únicamente quien le ha mantenido y le mantiene en la gloria y en el trono que oy posee han sido y son los españoles, con el solo auxilio de Francia. Y de todo esto queda para la posteridad una enseñanza cierta, de que los monarcas de España, para gozar la corona, han de poner su confianza solamente en los españoles": Carta, escrita a la muy noble y muy leal ciudad de Granada, en que el rey nuestro señor se sirve difundir los irregulares tratados con que la ambición de los enemigos tormentaba la paz, p. 10, cit. por CASTELLANO, Juan Luis: «El gobierno en los primeros años del reinado de Felipe V. La influencia francesa», en Pereira Iglesias, José Luis (coord.): Felipe V de Borbón (1701-1746), Córdoba, Ayto. de San Fernando-Universidad de Córdoba, 2002, pp. 131-42, p. 141. 
su propia nación o presionando para conseguir su caída- estas fuentes están llenas de suposiciones y valoraciones personales que hacen que no puedan ser utilizadas como fuentes objetivas (o al menos únicas) por los historiadores. No es extraño que Orry atribuyese en 1715 la desgracia de la princesa de los Ursinos a "une cabale d'Italiens qui se proposent depuis longtemps d'occuper les premiers emplois de la monarchie d'Espagne" ${ }^{80}$. Como tampoco que el duque de San Simón culpase a la cábala extranjera de perjudicar directamente a los españoles:

[...] les Italiens, qui se rassemblaient entre eux en cabale contre les Espagnols, sous la protection de la reine. Les Flamands s'accrochaient à eux pour plaire à la reine et par ancienne aversion de leur nation pour l'espagnole, et ce qu'il, y avait d'Irlandais aussi en officiers et en señoras de honor et en caméristes [...] Les Espagnols payaient de haine, de hauteur, de mépris, et en détestaient rien tant au monde que les Italiens, et après eux les Flamands. Ils souffraient les Irlandais, et la considération du roi, qui aimait fort les Français, les retenait à leur égard ${ }^{81}$.

La historiografía posterior acusó a muchos de estos extranjeros de ponerse al abrigo de la corte para alcanzar una rápida riqueza. Frente a personajes honestos como Macanaz, Ferrer del Río puso el ejemplo de Esquilache, cuya "práctica de los negocios ministeriales tenía mucha, cualidades de hombre de Estado pocas". O el de Ricardo Wall, quien "irlandés había nacido, y su fortuna, lenta al principio y rápida luego, ofrecía un ejemplo más de que España era entonces tierra de promisión para los aventureros de otros paises" ${ }^{\prime 2}$.

Esta injerencia directa extranjera en la corte - de Luis XIV y de su embajador francés durante los primeros años del reinado de Felipe V, italiana después con Alberoni- o bien indirecta sobre algunos ministros extranjeros -la supuesta anglofilia de Ricardo Wall-, también tuvo un peso importante en la moderna historiografía. Contamos con algunas contribuciones importantes de carácter general, como la de Ozanam sobre los extranjeros en la alta administración española del XVIII, y en la que este autor hunde las raíces del fenómeno en la necesidad de mano de obra cualificada para reconstruir la administración y el ejército borbónico de Felipe V entre 1700 y $1720^{83}$. Pero en el ámbito de la administración existe a simple vista una evidente desproporción en los estudios dedicados a los ministros de origen peninsular y los estudios sobre ministros de origen extranjero. Podríamos llenar páginas enteras de bibliografía sobre el madrileño José de Grimaldo ${ }^{84}$, el riojano marqués de Ense-

\footnotetext{
80 Ozanam, Didier: «Les étrangers dans la haute administration espagnole au XVIIIè siècle», en AmaLRIC, Jean Pierre (ed.): Pouvoirs et société dans l'Espagne moderne, Toulouse, Presses Universitaries du Mirail, 1993, p. 225.

81 Saint-Simon, Mémoires, ed. Chéruel, t. XIX, cap. 3.

82 Ferrer del Río: op. cit. (nota 11), I, pp. 244-248.

83 OzANAM: op. cit. (nota 80).

84 De Castro, C.: A la sombra de Felipe V. José de Grimaldo, ministro responsable (1703-1726), Madrid, Marcial Pons, 2004.
} 
nada $^{85}$, José de Carvajal ${ }^{86}$, los aragoneses conde de Aranda y Manuel de Roda ${ }^{87}$, los asturianos Campomanes y Jovellanos ${ }^{88}$, el murciano Floridablanca ${ }^{89}$ o el extremeño Godoy ${ }^{90}$. El adjetivo regional que antecede a estos personajes no es una cuestión baladí: en su época porque, como es sabido, el vínculo de paisanaje resultó un elemento importante en el origen de las redes clientelares; hoy día porque, como puede observarse por el lugar de edición de la bibliografía, este origen ha favorecido el apoyo institucional a la investigacion sobre estos individuos ${ }^{91}$.

Muchas menos páginas encontraríamos en el caso de ministros y otras personalidades extranjeras del XVIII español, como Alberoni, Ripperdá, Farinelli, Tanucci, Grimaldi, Esquilache u O'Reilly, entre otros. Sólo dos notorios personajes de origen extra-peninsular cuentan hasta el momento con recientes estudios: es el caso del peruano Pablo de Olavide, que ha dejado atrás la etiqueta de "afrancesado" (subtítulo de una de sus mejores biografías) por la de "ilustrado"92; y Ricardo Wall, el secretario de estado de origen irlandés estudiado por Téllez Alarcia ${ }^{93}$.

Como ocurrió en el caso de muchos de estos ministros, el empleo de mano de obra cualificada de origen extranjero también fue incentivada desde la propia corona. La promulgación de la primera ley en este sentido data de 1623 y establecía que los extranjeros católicos y "amigos de la Corona" pudieran establecerse libremente en los reinos españoles para ejercer oficios productivos ${ }^{94}$. Fue sin embargo en el siglo XVIII cuando el empleo de técnicos extranjeros alcanzó su cénit. Además de la compra de nuevos instrumentos y libros en el extranjero, para poner en práctica el ambicioso programa reformista se necesitaba contratar a técnicos especializados. El extranjero aportó la tradición y un know-how en muchos sectores ausentes en España, o al menos en la calidad más elevada. Esto se obser-

85 Gómez Urdáñez, José Luis: El proyecto reformista de Ensenada, Lleida, Milenio, 1996.

86 Molina Cortón, J.: José de Carvajal. Un ministro para el reformismo borbónico, Cáceres, Institución Cultural "El Brocense", 1999; Delgado Barrado, J.M.: El proyecto político de Carvajal. Pensamiento y reforma en tiempos de Fernando VI, Madrid, CSIC, 2001.

87 Olaechea, R. y Ferrer Benimeli, J.A.: El Conde de Aranda: mito y realidad de un político aragonés, Zaragoza, Librería General, 1978; Albiac Blanco, María Dolores: El Conde de Aranda: los laberintos del poder, Zaragoza, CAI, 1998; Ferrer Benimeli, José Antonio (dir.): El conde de Aranda y su tiempo. Congreso Internacional sobre "El Conde de Aranda y su tiempo" (1998, Zaragoza), Zaragoza, Institución Fernando El Católico, 2000, 2 vols.

88 Llombart, V.: Campomanes, economista y politico de Carlos III, Madrid, 1992; De Castro, C.: Campomanes. Estado y reformismo ilustrado, Madrid, 1996; Fernández Álvarez, Manuel: Jovellanos, Madrid, 1998; Baras Escolá, Fernando: El reformismo político de Jovellanos. Nobleza y poder en la España del siglo XVIII, Zaragoza, Universidad de Zaragoza, 1993.

89 Hernández Franco, Juan: La gestión politica y el pensamiento reformista del Conde de Floridablanca, Murcia, Universidad de Murcia, 1984 y Aspectos de la política exterior de España en la época de Floridablanca, Murcia, Academia Alfonso X el Sabio, 1992; Alberola Romá, Armando (coord.): El conde de Floridablanca y su época, Dossier des Mélanges de la Casa de Velázquez. Nouvelle série, 39 (2), 2009.

90 La Parra López, Emilio: Manuel Godoy: la aventura del poder, Barcelona, Tusquets Editores, 2002.

91 Sin ir más lejos, la publicación de las Obras completas de Jovellanos, en 11 volúmenes, a cargo del Centro de Estudios del Siglo XVIII (Oviedo) y del Ayuntamiento de Gijón entre 1984 y 2006.

92 Défourneaux, Marcelin: Pablo de Olavide. El afrancesado, México, 1965; Perdices Blas, Luís: Pablo de Olavide (1725-1803): El ilustrado, Madrid, 1993.

93 Téllez Alarcia, Diego: D. Ricardo Wall. Aut Caesar aut nullus, Madrid, Ministerio de Defensa, 2008 y Absolutismo e Ilustración en la España del siglo XVIII. El despotismo ilustrado de D. Ricardo Wall, Madrid, 2010.

${ }_{94}$ Novísima Recopilación de las Leyes de España, Ley VIII, Libro VI, Titulo XI (ed. Madrid, 1805), p. 165. 
va en el programa de reconstrucción de la armada llevado a cabo por Ensenada. Además de seguir atentamente las técnicas inglesas, se contrató a ingenieros y técnicos navales ingleses e irlandeses, que normalmente doblaban el salario de sus colegas españoles ${ }^{95}$. Los extranjeros también estuvieron muy presentes en los empleos de alta cualificación requeridos por la corte -arquitectos y pintores, modistas, médicos, músicos y relojeros- y fuera de la corte los proyectos ilustrados de fomento de la agricultura también impulsaron la presencia en España de artesanos y especialistas extranjeros. Son bastante conocidos los planes de repoblación de áreas deshabitadas en España ${ }^{96}$.

\section{CONCLUSIONES}

La inmigración extra-peninsular en España fue vista desde la propia época con una mezcla de sospecha y necesidad. Desde un punto de vista social, los extranjeros podían introducir ideas peligrosas u hostiles a la ortodoxia religiosa; desde el punto de vista económico fueron vistos como especuladores en el terreno financiero y como competidores a nivel local en el ámbito comercial. Sin embargo, la Monarquía, en su dimensión global, no podía prescindir de los individuos no regnícolas y el rey se convirtió en el principal empleador y beneficiario de esta presencia: desde el punto de vista político-militar, el extranjero tenía a la figura del monarca como su máximo referente y podía actuar como contrapeso a las poderosas élites nobiliarias tradicionales del reino; desde el punto de vista científico-tecnológico, económico e incluso cultural, el objetivo era atraer a mano de obra cualificada en distintos sectores.

La historiografía decimonónica hizo suyas las críticas de muchos contemporáneos. La influencia de los extranjeros en la corte fue convertida en injerencia y fueron así incorporados a la historia nacional como claros ejemplos de la decadencia del antiguo régimen. Esta decadencia alzanzó su clímax en el XVIII, el siglo "extranjero" por excelencia. La historiografía moderna española continuó el debate sobre la influencia-injerencia extranjera, señalando la "españolización" de la administración española tras la salida de España del embajador Amelot o las reformas militares. En la actualidad se empieza a enmarcar el estudio de estos individuos y comunidades en la sociedad española del antiguo régimen, constituyendo un reto importante la comparación de los distintos modelos y redes de nación. Si tuviéramos que buscar un denominador común a todos los estudios recientes sobre el tema, sin duda sería su heterogeneidad. El estudio sobre las comunidades extranjeras en España puede ser abordado desde los más diversos puntos de vista: transversalmente aparece en temas relacionados con los movimientos migratorios y exilios, con la historia económica y la historia social y cultural, con la historia local y de la religión, o con los temas relacionados con identidad y la integración.

\footnotetext{
95 Lafuente, Antonio y Peset, José Luis: «Política científica y espionaje industrial en los viajes de Jorge Juan y Antonio de Ulloa (1748-1751)», Mélanges de la Casa de Velázquez, 17 (1981), pp. 233-262.

96 Ver los estudios recogidos por Avilés, M. y SEnA, G. (eds.): Nuevas poblaciones en la España Moderna, Córdoba, UNED, 1991.
} 